\title{
LUTAS, RESISTÊNCIAS E DESAFIOS DA EDUCAÇÃO BÁSICA CONTRA O ENSINO REMOTO
}

\author{
FIGHTS, RESISTANCE AND CHALLENGES OF BASIC EDUCATION \\ AGAINST REMOTE EDUCATION
}

\author{
Isabella Vitória Castilho Pimentel Pedroso ${ }^{1}$ \\ EBTT COLUNI UFF \\ isabellavitoria@id.uff.br \\ Angelo Fernando Pereira ${ }^{2}$ \\ Secretaria de Estado de Educação do Rio de Janeiro \\ angelofernando@id.uff.br
}

\section{Resumo}

Este artigo surge a partir dos diálogos e discussões na $12^{\mathrm{a}}$ Mesa redonda intitulada: Conversa com a FEUFF, ocorrida em julho de 2020, promovida pela Faculdade de Educação da Universidade Federal Fluminense. O encontro contou com a participação de professores do ensino básico público das redes estadual e federal do Rio de Janeiro, onde destacaram-se suas considerações sobre a organização do ensino remoto em tempos de pandemia, refletindo a consistência dos novos modelos pedagógicos implantados nos cotidianos dos alunos e nas práticas docentes. Também buscou-se entender a aplicação dos novos instrumentos e métodos da educação, mediante o distanciamento imposto no período entre professores e alunos, com vistas à organização e aos propósitos do ensino remoto. De fato, os autores se viram diante de um enorme desafio, uma vez que a discussão é muito recente e requer mais reflexões sobre suas representações e objetivos pedagógicos.

\section{Palavras-chave}

Educação básica; Ensino remoto; Pandemia.

\begin{abstract}
This article arises from the dialogues and discussions at the 12th Roundtable entitled: Conversation with FEUFF, which took place in July 2020, promoted by the Faculty of Education of Universidade Federal Fluminense. The meeting was attended by teachers of public basic education from the state and federal networks of Rio de Janeiro, where their considerations on the organization of remote education in times of pandemic stood out, reflecting the consistency of the new pedagogical models implemented in the daily lives of students and teaching practices. We also sought to understand the application of new instruments and methods of education, through the distance imposed in the period between teachers and students, with a view to the organization and purposes of remote education. In fact, the authors faced an enormous

\footnotetext{
${ }^{1}$ Docente EBTT COLUNI - UFF. Doutora em Geografia pela Universidade Federal do Rio de Janeiro (UFRJ)

${ }^{2}$ Docente na Secretaria de Estado de Educação do Rio de Janeiro. Doutorando em Arquitetura e Urbanismo pela Universidade Federal Fluminense (UFF)
} 


\section{Ensaios de Geografia}

Essays of Geography | POSGEO-UFF

challenge, since the discussion is very recent and requires more reflections on their representations and pedagogical objectives.

Keywords

Basic Education; Remote teaching; Pandemic.

\section{Introdução}

No contexto da pandemia, o ano de 2020 revelou-se desafiador nos processos de ensino e aprendizagem para alunos, professores e demais profissionais da educação básica em todo mundo. No Brasil, as atividades pedagógicas nas escolas foram suspensas e, em um segundo momento, substituídas por ações remotas, visando a manutenção do distanciamento social, exigida pelo período. Com isso, cada sistema de ensino e esfera de poder puderam escolher, definir suas estratégias de reposição de conteúdos e de amparos pedagógico e social aos seus alunos. Neste cenário, o meio eletrônico foi o escolhido por grande parte das escolas para a comunicação com os alunos e seus responsáveis, como os aplicativos de mensagens, redes sociais, e-mail e plataformas digitais próprias ou mantidas por grupos empresariais.

Todo esse aparato remoto, montado às pressas pelas instituições de ensino, reacendeu nos profissionais da educação o alerta da implantação do ensino híbrido, que combina ações pedagógicas presenciais e virtuais (CANNATÁ, 2017, p. 60) e da própria sistematização da educação à distância (EAD) na educação básica, fora dos tempos de pandemia. Laval (2019) afirma que este cenário é parte do avanço neoliberal sobre o sistema de ensino, sobretudo o da educação básica, evidenciando a face excludente em relação aos alunos e acentuando a precarização do trabalho para os professores (STEVANIM et al., 2020). Além disso, vale destacar os interesses financeiros nas propostas de grupos empresariais da área de educação, que apresentam um modelo remoto com parcialidade, sem preocupar-se com os aspectos psíquicos e cognitivos dos sujeitos que o receberão.

Portanto, pensemos no significado da palavra "remoto". Para o Dicionário Michaelis (2015), representa afastamento no tempo/espaço, ou seja, algo que separa corpos fisicamente, não havendo, necessariamente, sincronia e sintonia entre os mesmos. Na educação básica, o ensino remoto é uma prática antiga de compensação pedagógica 


\section{Ensaios de Geografia}

Essays of Geography | POSGEO-UFF

pelo distanciamento entre alunos e professores, com a supressão das aulas presenciais, sob diversas condições, como viagens, doenças ou o fechamento temporário de estabelecimentos de ensino. Sob diversos nomes, essas ações têm sido utilizadas para reposição de aula, como em períodos pós-greve, em dependência de disciplina (caso haja reprovação do aluno) ou na ausência de um determinado professor. Geralmente, o ensino remoto, no calendário regular, ocorre por um curto período de tempo e suas práticas se adequam às condições e situações postas, observando os cotidianos momentâneos dos envolvidos. Vale ressaltar que as atividades remotas são garantidas na Lei de Diretrizes e Bases da Educação (LDB, 1996), em seu artigo $4^{\circ}$ e, está submetida ao entendimento da equipe pedagógica das escolas como um direito dos educandos.

Como abordado acima, tal discussão foi fomentada na $12^{\mathrm{a}}$ Mesa redonda: Conversa com a FEUFF, junto a professores da rede básica de ensino de Niterói, sob o contexto do ensino remoto no período da pandemia e suas implicações nos cotidianos de alunos e professores. Como desdobramento desse debate, nós, professores de geografia da rede básica, nos propusemos a aprofundar a pesquisa do tema a partir de nossas vivências. Procuramos contextualizar a organização desse novo modelo de ensino e suas implicações a partir da comunicação mantida entre os membros da comunidade escolar, sob um olhar crítico do ambiente virtual de aprendizagem/ensino, além de promover intensa revisão bibliográfica focada na área de educação.

\section{Conflitos no ensino remoto na rede estadual de ensino do Estado do Rio de Janeiro}

Em função do período de pandemia no país, o Conselho Nacional de Educação (CNE) deliberou que estados e municípios, através do parecer 5/2020, poderiam emitir resoluções sobre a organização do ensino remoto e suas orientações no desenvolvimento das atividades não presenciais. A partir disto, o Conselho Estadual de Educação do Rio de Janeiro (CEE-RJ) orientou na deliberação 376/2020, que as escolas da rede básica de ensino público promovessem suas próprias estratégias em "atividades domiciliares", junto ao seu corpo docente, contando com ações estruturais e metodológicas, não tendo criado obrigações quanto ao uso de ferramentas eletrônicas nesse processo.

AO CITAR ESTE TRABALHO, UTILIZAR A SEGUINTE REFERÊNCIA:

PEDROSO, Isabella Vitória Castilho Pimentel; PEREIRA, Angelo Fernando. Lutas, resistências e desafios da educação básica contra o ensino remoto. Revista Ensaios de Geografia. Niterói, vol. 7, nº13, pp. 49-56, janeiro-abril 2021.

Submissão em: 26/02/2021. Aceito em: 08/03/2021. 


\section{Ensaios de Geografia}

Essays of Geography | POSGEO-UFF

De necessidade de situações excepcionais nas escolas às "gambiarras pedagógicas", o ensino remoto na rede pública estadual de educação do Rio de Janeiro foi condicionado, às pressas, à Educação a Distância pela plataforma digital Google Classroom como um Ambiente Virtual de Aprendizagem (AVA), devendo estabelecer um canal de comunicação entre alunos e professores. Ao contrário do ensino remoto usual, das folhas de papel e apostilas impressas, esse novo modelo foi implementado sobre uma estrutura eletrônica codificada, com ações pedagógicas que se prolongaram por todo o ano de 2020, exigindo o uso de computadores e celulares e o conhecimento prévio de aplicativos e programas de informática.

Os problemas dos alunos na plataforma Google Classroom surgiram logo no primeiro momento de obrigatoriedade de acesso ao sistema, principalmente àqueles relacionados às questões instrumentais. Mas, antes de pensarmos sobre as atuais condições tecnológicas em que os alunos têm tido ao longo da pandemia, temos outras questões pendentes para refletirmos. Quais são as origens dos nossos alunos? Qual educação o sistema lhes proporcionou ao longo dos anos? Quais são suas necessidades pessoais e suas condições socioeconômicas? Quais são as dificuldades que têm enfrentado na pandemia? Temos de encontrar essas respostas antes de pensarmos em uma proposta pedagógica momentânea e coerente às suas realidades.

Vale lembrar que, durante a pandemia, além da ruptura drástica da vivência no ambiente escolar para o ensino remoto, os alunos foram obrigados a se manterem em casa por mais tempo durante o dia. E, para muitos estudantes, a escola é um ambiente livre de abusos, um ambiente plural, onde podem se expressar e serem reconhecidos por suas identidades, é um espaço de sociabilidade, afetos (ORNELLAS, 2005) e, que garante a segurança alimentar para muitos.

Quando pensamos no ensino remoto no período e toda a montagem de uma plataforma eletrônica de execução de tarefas, com uma linguagem técnica, embasada na informática: documentos, vídeos, links, esquecemos todas as condições ambientais, socioafetivas e financeiras tidas por esses alunos. Muitas situações de impedimento à execução de trabalhos no Google Classroom foram relatadas pelos mesmos aos profissionais da rede, como o fato de não terem um lugar propício aos estudos em casa, 


\section{Ensaios de Geografia}

Essays of Geography I POSGEO-UFF

não terem acesso facilitado à internet, não possuírem um computador, por terem de dividir um único aparelho de celular com os irmãos e mesmo, não terem um aparelho de celular. Também foram relatados casos de alguns alunos terem de gerar renda junto às suas famílias, realizando trabalhos informais no período e, outros por estarem doentes ou cuidando de familiares doentes e até por estarem sem condições psicológicas satisfatórias para fazê-la.

As tentativas da Secretaria de Educação ao querer impor um regime de obrigatoriedade de acesso de alunos e professores ao sistema resultaram no protesto de pais, responsáveis e do sindicato de professores (SEPE-RJ). Com isso, flexibilizou-se a forma como os alunos cumpririam suas atividades pedagógicas: foram impressas e entregues, presencialmente ou pelos correios, as Atividades Autorreguladas (apostilas produzidas pela própria secretaria) e muitos professores passaram a receber trabalhos enviados pelo aplicativo de mensagens WhatsApp. Mais uma vez, com todo esse afastamento entre alunos e professores, muitos estudantes relataram ter tido dificuldades em compreender as atividades propostas. E, com essas incertezas, ocorreu um aumento do número de alunos que não realizaram mais as atividades na plataforma, com prejuízos ao seu direito à educação - nem se fala mais em direito à educação "de qualidade". Finalizado o ano letivo, foram promovidos (aprovados) aqueles que puderam comprovar ter realizado alguma atividade proposta, seja ela eletrônica, impressa ou ter afirmado que assistiu às aulas na mídia televisiva.

\section{Qual ensino remoto queremos? A resistência de um colégio universitário federal}

A diferença substancial entre as duas experiências aqui relatadas está no fato de uma ter sido imposta pela secretaria estadual, como abordado acima, e a outra ter sido pensada exclusivamente por professores, preocupados com a situação psíquica, social e econômica de cada aluno. A rede pública federal goza de maior autonomia e, por isso, cada instituto federal e colégio de aplicação puderam formular suas estratégias para o período. Neste relato, a experiência de um colégio universitário será descrita.

Após o fechamento da escola, em 13 de março de 2020, docentes e discentes se viram em um cenário inusitado. Não havia certeza sobre o dia de retorno e ainda não se 


\section{Ensaios de Geografia}

Essays of Geography I POSGEO-UFF

cogitava qualquer possibilidade de ensino remoto, embora a universidade a qual nos vinculamos já esboçava caminhos para a implantação dessa modalidade. À época nos posicionamos em nota e nos reunimos com os responsáveis para garantir-lhes que o ensino à distância não cabia em nosso projeto de ensino e, portanto, iríamos esperar o tempo que fosse para retomar nossas atividades com segurança.

Mesmo com toda nossa firmeza em não retomar as atividades de ensino, a pressão feita pela reitoria e também pela própria sociedade foi enorme. Diante disso, realizamos uma pesquisa detalhada para compreender a situação de acesso à internet e de condições de saúde deles mesmos e de seus familiares. A pesquisa identificou que mais de $90 \%$ dos nossos alunos possuíam acesso à rede e aqueles que não possuíam seriam beneficiados com o recebimento de chip e computadores, cedidos pela universidade. Diante dessa certeza, iniciamos a construção de um site, que seria o local virtual onde nossa interação aconteceria. Vale dizer, o site foi concebido e criado pelos professores de todos os segmentos e de diferentes áreas do conhecimento pertencentes ao corpo da escola.

Com o site criado, a questão se colocou com ainda mais força: qual ensino remoto queremos? Após intensos debates, reafirmamos nosso compromisso com a não adesão à EAD e à não transposição de aulas remotas em um ambiente virtual. Para isso, tivemos que romper com toda estrutura de ensino que conhecíamos até então. Diferentemente do que se concebeu para o ensino estadual, criamos o AVE (ambiente virtual de ensino), uma vez que a proposta se daria da seguinte maneira: as atividades postadas no site seriam feitas e trabalhadas pelas áreas de conhecimento e não por disciplinas isoladas; a organização escolar passa a ser por ciclos e não séries; notas numéricas foram substituídas por conceitos; avaliações formais foram substituídas por relatórios de aprendizagem. Em outras palavras, modificamos totalmente a estrutura de ensino que conhecíamos.

Os alunos se mostraram muito receptivos à ideia, entenderam que este é um momento de maior autonomia deles e que seria possível dar continuidade aos estudos a partir desse novo método de aprendizagem. Além disso, para cumprir as determinações impostas pela universidade, neste total de atividades, 30\% seriam encontros síncronos, quando, ao invés de darmos aulas formais, aprofundamos o debate e sanamos possíveis dúvidas. Essa tem sido uma experiência ímpar de ensino-aprendizagem da escola. Nesse

AO CITAR ESTE TRABALHO, UTILIZAR A SEGUINTE REFERÊNCIA:

PEDROSO, Isabella Vitória Castilho Pimentel; PEREIRA, Angelo Fernando. Lutas, resistências e desafios da educação básica contra o ensino remoto. Revista Ensaios de Geografia. Niterói, vol. 7, nº13, pp. 49-56, janeiro-abril 2021.

Submissão em: 26/02/2021. Aceito em: 08/03/2021. 


\section{Ensaios de Geografia}

Essays of Geography I POSGEO-UFF

momento de tragédia que vivemos, nossa proposta é que os alunos tenham contato com as diferentes formas de artes (música, cinema, pintura), com diferentes autores e pontos de vista. Além disso, a intenção é fazer com que eles tenham uma carga menos pesada de trabalho e que seja um momento de prazer, em meio a tudo isso que vivemos. Neste cenário de tristeza e abandono governamental que vivemos, estamos resistindo à agenda do capital e assegurando aos nossos alunos que a escola seja um local de acolhimento e segurança, mesmo que virtual.

\section{Considerações Finais}

Entendendo as diferenças e dimensões entre as redes estadual e federal de ensino no Rio de Janeiro no período de 2020, abrimos um grande leque de reflexões sobre políticas públicas e suas diretrizes na educação básica. Ressaltamos nossa preocupação com os limites à liberdade de cátedra e a intervenção institucional nas escolas e, a implantação sistemática do ensino remoto no pós-pandemia, com vistas à financeirização do sistema e uma diminuição dos investimentos públicos no setor.

Como, também refletimos sobre os métodos e objetivos do trabalho docente mediante os antigos e novos cenários colocados para a educação básica. Sustentamos existir um conflito entre a chamada educação bancária, tradicional, ainda centrada na figura do professor (FREIRE, 1997) nas escolas e que pouco reflete sobre ações focadas na autonomia do aluno (FREIRE, 2005) e uma educação centrada em uma plataforma eletrônica, sem ânimo, causando estranhamento entre todos os envolvidos. Ou seja, transpusemos a gambiarra pedagógica do papel para o meio digital, aumentando a exclusão social e tecnológica, já existentes.

No decorrer do artigo, os autores se propuseram a levantar a discussão sobre o "modelo de ensino emergencial remoto que queremos". Portanto, levando-se em consideração as atuais condições socioeconômicas e afetivas dos alunos e o uso das práticas tradicionais de ensino, conclamamos aos leitores, sobretudo os colegas professores da educação básica, a repensar a condução de um ensino emergencial remoto que garanta o direito dos alunos ao acesso à uma educação de qualidade, inclusiva e que respeite as individualidades. Somos nós, partícipes da comunidade escolar, que devemos 


\section{Ensaios de Geografia}

Essays of Geography I POSGEO-UFF

promover essa reorganização metodológica coerente e responsável, garantindo sentido ao processo de ensino-aprendizagem para todos nesse período excepcional que nos encontramos. A luta, portanto!

\section{Referências Bibliográficas}

BRASIL, L. D. B. Lei 9394/96-Lei de Diretrizes e Bases da Educação Nacional. Disponível em: <http://www. Planalto. gov. br/ccivil_03/leis/19394. htm>. Acesso em: 7 ago. 2020.

CANNATÁ, VERÔNICA. Ensino Híbrido na Educação Básica: narrativas docentes sobre a abordagem metodológica na perspectiva da personalização do ensino. 2017.

DAYRELL, Juarez. A escola como espaço sócio-cultural. Múltiplos olhares sobre educação e cultura. Belo Horizonte. UFMG, v. 194, pp. 136-162, 1996.

DE ARAÚJO, Patrícia Silva Rosas; PEREIRA, Paulo Ricardo Ferreira. OS DESAFIOS DO ENSINO REMOTO NA EDUCAÇÃO BÁSICA com Denise Lino de Araújo. Revista Leia Escola, v. 20, n. 1, pp. 231-239, 2020.

FREIRE, Paulo. Educação "bancária" e educação libertadora. Introdução à psicologia escolar, v. 3, pp. 61-78, 1997.

FREIRE, Paulo. Pedagogia da autonomia: saberes necessários à prática educativa. São Paulo: Paz e Terra, 1996. Coleção leitura, p. 21, 2005.

LAVAL, Christian. A Escola não é uma empresa: o neoliberalismo em ataque ao ensino público. São Paulo: Boitempo, 2019.

LEMOS, Fabiano. O que é um modelo pedagógico? Contribuições filosóficas a um problema de metodologia histórica. Educação, Sociedade e Cultura, pp. 155-171, 2017.

ORNELLAS, Maria de Lourdes Soares. Afetos manifestos na sala de aula. Annablume, 2005 .

PEREIRA, Evaldo Magno Anchieta; DOMINGO, Reinaldo Portal. O Ambiente Virtual de Aprendizagem na Educação Básica: Uma Experiência com o EDMODO no EnsinoAprendizagem de Artes Visuais. Revista Brasileira de Aprendizagem Aberta e a Distância, v. 17, n. 1, 2018.

"REMOTO". Dicionário Michaelis. Editora Melhoramentos, 2015. Disponível em: $<$ http://michaelis.uol.com.br/busca? $\mathrm{r}=0 \& \mathrm{f}=0 \& \mathrm{t}=0 \&$ palavra $=$ remoto $>$. Acesso em: 8 ago. 2020 .

STEVANIM, Luiz Felipe et al. Exclusão nada remota: desigualdades sociais e digitais dificultam a garantia do direito à educação na pandemia. 2020.

AO CITAR ESTE TRABALHO, UTILIZAR A SEGUINTE REFERÊNCIA:

PEDROSO, Isabella Vitória Castilho Pimentel; PEREIRA, Angelo Fernando. Lutas, resistências e desafios da educação básica contra o ensino remoto. Revista Ensaios de Geografia. Niterói, vol. 7, nº13, pp. 49-56, janeiro-abril 2021.

Submissão em: 26/02/2021. Aceito em: 08/03/2021.

ISSN: 2316-8544 